'Ilu. Revista de Ciencias de las Religiones

ISSN: $1135-4712$

http://dx.doi.org/10.5209/ILUR.57420

\title{
Estética del abandono: el retiro de monjas budistas ${ }^{1}$
}

\author{
María Elvira Ríos²
}

Recibido: 24 de enero de 2017 / Aceptado: 13 de junio de 2017

Resumen. En busca de un lugar idóneo para las prácticas ascéticas, las monjas budistas chinas se insertan en la montaña y se refugian en un lugar que les permita estar en retiro. Entre estos lugares hallamos templos abandonados; espacios que comúnmente son utilizados por religiosos. ¿Hay alguna cualidad o característica particular del espacio abandonado que, para la religiosa, adquiera un valor distinto para su práctica? ¿Qué es lo que el espacio abandonado provoca o transmite a la religiosa? ¿Se produce un vínculo entre el espacio físico y la experiencia de conciencia plena alcanzada en la práctica interior? El presente artículo analiza la experiencia de una monja budista en un templo abandonado en la montaña Nanwutai, en Zhongnan-shan. En el análisis se propone que la estética del espacio abandonado colabora en la manera en que la religiosa interpreta el alcance de una conciencia plena, que se traduce como la unión del espacio interior con el exterior, por lo tanto, la liberación de toda atadura y la comprensión del universo budista.

Palabras clave: Budismo contemporáneo; religiones de China; ascetismo; montañas sagradas.

\section{[en] Abandoned Aesthetic: The Seclusion of the Buddhist Nuns}

\begin{abstract}
In search of a suitable place for ascetic practices, Chinese Buddhist nuns travel well into the mountains and take shelter in places that allow them to be in seclusion. Among these places we find abandoned temples; spaces that are commonly used by religious people. Is there any quality or characteristic of abandoned spaces such that it becomes of special value for the practice of religious women? What does the abandoned space provoke or transmit to the nun? Does it produce a connection between physical space and the higher consciousness experience achieved in inner practice? This paper analyzes the experience of a Buddhist nun in an abandoned temple on Nanwutai Mountain in Zhongnan-shan. In this analysis, we propose that the aesthetics of the abandoned space influences the way in which the nun interprets the attainment of a pure consciousness. This may be understood as the union of both interior and exterior spaces, and as such, the liberation of all restraints and the ultimate comprehension of the Buddhist universe.
\end{abstract}

Keywords: Contemporary Buddhism; Chinese religion; asceticism; sacred mountain.

Sumario. 1. Introducción. 2. Monjas en el budismo chino: trasfondo histórico. 3. Un templo, una monja. 4. Unión de espacios: percepción de la conciencia plena. 5. Conclusiones y reflexiones finales. 6 Bibliografía.

Cómo citar: Ríos, M. E. (2017), Estética del abandono: el retiro de monjas budistas, en 'Ilu. Revista de Ciencias de las Religiones 22, 343-357.

\footnotetext{
1 Parte de la información recopilada en este texto pertenece a la investigación de la tesis de doctorado, durante la estancia de investigación en 2011, China.

2 Universidad del Desarrollo (Chile).

E-mail: mariaelvira.rios.p@gmail.com
} 


\section{Introducción}

El concepto en chino que se utiliza para referirse a un devoto religioso es chujia 出家 ${ }^{3}$, que literalmente significa «salir del hogar». La acción de salir del espacio familiar es el primer abandono o renuncia que deberá realizar el novicio o la novicia budista; después vendrán otros, como abandonar los fannao 烦恼 (kleśa en sánscrito), aquellas turbaciones: alteraciones del ánimo y del pensamiento, que producen el karma ${ }^{4}$, para luego renunciar a la propia idea del yo ${ }^{5}$. La renunciación es intrínseca en el camino hacia la liberación. El proceso de alcanzar la liberación se puede ver como una renuncia sucesiva a la condición humana, y para iniciar este proceso es preciso transformar el estilo de vida y el comportamiento ${ }^{6}$.

En este estudio se propone analizar el retiro en un templo abandonado desde la percepción y experiencia de una monja budista. En el análisis se sugiere que, el templo en estado de abandono, con sus muros derruidos y pintura desgastada, se presenta como eco del espacio interior de la practicante. La religiosa, en el proceso de una práctica de meditación profunda, busca liberarse de las turbaciones internas, produciendo una unión entre el mundo exterior y el interior, que se logra con la observación detenida y constante ${ }^{7}$, vipaśyana , la cual permite discernir lo real de lo no real, y comprender todo el universo. En la reflexión en torno a esta unión, interactúan elementos de la estética del espacio abandonado y de la doctrina budista. Asimismo, para que sea efectiva esa interacción la practicante experimenta ganying 感应 con el lugar. El concepto de ganying está implícito en la cosmología china, en la que los cinco elementos confluyen y, por medio de esta resonancia-sympathetic o "estímulo-respuesta», crean el universo ${ }^{8}$. Sobre el concepto ganying y del ejemplo anterior, Graham señala que si consideramos el concepto de ying, «respuesta», desde la perspectiva neurológica, se podría decir que se refiere a las reacciones espontáneas que preceden al pensamiento, a esa acción natural que resulta cuando surge algo y espontáneamente hay una respuesta 9 .

3 Chujia en chino se relaciona con la traducción del concepto sánscrito de Pravrajyā, definido como el rito que realiza un laico o laica en el que se convierte en un novicio o novicia budista. Una bhikṣuñ es una mendicante religiosa quien ha renunciado a la vida mundana para seguir la huella del Buda hacia la iluminación y liberación del sufrimiento. Ella no tiene otro sustento que su vida religiosa, y recibe donaciones de comida, vestuario y cobijas desde los devotos laicos. Generalmente el término bhikșuṇi se ha traducido como monja, pero esta analogía es sólo aproximada. Al igual que su contraparte masculina (bhikșu), las bhikṣun̄i pasan un periodo de entrenamiento como novicias, después son ordenadas como monjas en una ceremonia conocida como upasampadā (Barnes 2000, 17).

4 Traducción al castellano de Luis. O. Gómez Rodríguez para la palabra en sánscrito kleśa.

5 Desde antaño, los chinos habían adquirido la práctica de retiro para alejarse de la sociedad, retirándose en la naturaleza, para reflexionar sobre los problemas que imperaban en el reino. La idea de la vida de retiro (yindun 隐遁) en el Zhouyi la encontramos en el hexagrama de dun 遁, en cuya imagen se señala: «Bajo el cielo hay montañas, retiro.» En el hexagrama vemos el Cielo, qian 乾 arriba, y abajo gen 艮 montaña; la acumulación de yang es cielo y la acumulación de yin es tierra. La montaña es lo más alto de la tierra. La montaña cercana al cielo es la imagen del yin grande y la naturaleza superior. (Zhang y Min 2016, 1). Asimismo, como parte del rito de piedad filial, cuando fallecía el padre de una familia, el hijo debía retirarse por tres años.

6 Blackstone 2000, 37.

7 Traducción al castellano de Luis. O. Gómez Rodríguez para la palabra en sánscrito vipaśyanā.

8 Sharf 2002, $82 \mathrm{~s}$. Sharf afirma que el ganying vinculado con la cosmología china se entiende como una respuesta espontánea y natural en un universo concebido holísticamente como un orden interdependiente. La noción de «resonancia» se utilizó en la dinastía Han para explicar los mecanismos de un sistema elaborado con categorías correlacionadas, generalmente conocidas como las wuxing, las cinco-fases 五行.

9 Graham 1989, 244 s. 
La sensación de ganying del practicante con el lugar teje la unión entre el espacio interior y exterior, colaborando en la percepción de integración de ambos espacios. Finalmente, y aunque no ahondaremos en un estudio de género, el que nuestro sujeto de análisis sea una mujer, adquiere una connotación distinta a la de un monje en retiro, lo que nos llevará a desarrollar brevemente la historia de las monjas budistas en China y algunas referencias importantes que se manifestarán en la religiosa.

\section{Monjas en el budismo chino: trasfondo histórico}

La incorporación de la mujer en el mundo eclesiástico budista no fue del todo fácil. Conocida es la historia de Mahāprajāpatī, tía del Buda, quien gracias al apoyo de Ānanda, el Buda acepta la formación de la primera congregación de bhikṣuñi o monjas budistas ${ }^{10}$. Ellison Banks señala al menos cuatro áreas en las que la mujer budista ha encontrado obstáculos en su vida espiritual. La primera se refiere a las prácticas religiosas, (costumbres en el estilo de vida), las oportunidades de enseñanza, las formas de meditación y las estructuras institucionales. Banks afirma que los textos canónicos mencionan claramente que la mujer puede experimentar la iluminación, pero las vías para progresar en esta experiencia usualmente son truncadas. La completa e irreversible transformación de la iluminación budista la alcanzan por medio de una lenta y ardua disciplina. La segunda, son las reglas disciplinarias las que, con respecto a las reglas de los monjes, están diseñadas para personas de segunda clase. Un ejemplo esclarecedor son las ocho reglas para las monjas que instaura el Buda ${ }^{11}$. La tercera, aunque la mujer es capaz de lograr la experiencia de la iluminación, el reconocimiento de esa experiencia superior, en términos de título y estatus, usualmente es retenida en la historia del budismo. El término en pāli de arahant (en sánscrito $a r h a t)^{12}$, por ejemplo, no se empleaba a mujeres en los textos tempranos, aunque la narrativa de conversión e iluminación de un número de mujeres era evidente. Esto mismo sucede con la tradición Mahāyāna y el término de bodhisattva ${ }^{13}$. Finalmente, tanto como individuos y como miembros de las comunidades de la sangha, las monjas han recibido donaciones, pero este material ha sido notoriamente menor con respecto a lo que se ha entregado a los monjes renunciantes ${ }^{14}$.

10 En el Bhikșun̄ikarmavācanā del Libro de la Disciplina (Vinaya Pițaka), se relata que Ānanda intercedió a favor de Mahāprajāpatī, para que el Buda permitiera la ordenación de monjas.

11 El Buda dio a Ānanda la instrucción de las ocho reglas (gurudharma) que deben seguir las monjas: 1. La monja puede recibir la ordenación solamente en presencia de once monjes. 2. Una vez al mes la monja aprende la enseñanza y las instrucciones directamente de los monjes, puesto que la monja no puede enseñar el Dharma. 3. En la época de lluvias, las monjas deben estar en lugares donde no haya monjes. 4. Al final de la época de lluvias, la monja debe hacer la ceremonia del final de la época de lluvias en presencia de monjes y monjas. 5. Se prohíbe que una monja acuse o vaya en contra de algún monje. 6. Una monja no puede molestar o reprender a un monje. 7. Cuando una monja viola una regla recibe un castigo cada medio mes. 8. Una monja de cien años también debe ser respetuosa con un monje, saludarlo con las palabras correctas y hacer una reverencia (Faure 2003, 23).

12 El arhat es quien ha alcanzado un nivel superior en la práctica y ha adquirido poderes extraordinarios.

13 El bodhisattva [...] ser (sattva) dedicado por entero a la consecución del despertar (bodhi) [...] quienes han hecho el voto (praṇidhāna) de alcanzar el despertar perfecto y completo con el fin de rescatar a todos los seres del renacer y el sufrir [...]. Los bodhisattva protagonizan toda una mitología de prodigios y leyendas similares a las que otras tradiciones asocian a dioses y santos (Arnau, 2007, 197).

14 Banks 2000, 3. Los estudios acerca de la participación de la mujer en el clero budista son diversos; unos recalcan en el papel inferior de la monja y la superioridad del monje y otros destacan episodios de la historia del budismo en que se resalta la sabiduría de una monja y sus capacidades. Bernard Faure señala que la realidad de las mon- 
En China, la vida monástica entre los monjes y las monjas se dividió, por lo que las monjas tenían más independencia y la institución era administrada por y para las religiosas ${ }^{15}$. De lo anterior surgió el interés en escribir las biografías de 65 monjas eminentes, plasmadas en el Biqiuni-zhuan. Estas historias abarcarían la vida de monjas desde principios de siglo IV hasta principios del siglo $\mathrm{VI}^{16}$.

Las primeras monjas que se registran en los conventos tenían desde 5 o 6 hasta 70 años. Aquellas que, por decisión personal, querían ingresar al convento debían contar con el permiso de la persona que tenía autoridad sobre ellas, es decir, el padre, el esposo o el hijo. En su mayoría llegaban por aspiraciones religiosas, veían al convento como refugio de las vicisitudes de la vida, tanto familiares como sociales (guerras, epidemias, etcétera.). Otras, para seguir estudios académicos, los que mayormente tenían prohibido en la vida secular ${ }^{17}$.

A pesar de las biografías escritas, la información que se recopiló fue y continúa siendo muy escasa ${ }^{18}$. Durante la Dinastía Song (960-1279), la mujer adquiere mayor importancia en la sociedad, aumenta su participación en las actividades religiosas y se desarrolla un discurso distinto hacia su figura. En ese periodo, la corriente Chan comienza a tomar en cuenta en su discurso a la mujer, y con ello logra distinguirse de las demás corrientes. Al mismo tiempo, el budismo funciona como un refugio, que permite a la mujer desligarse de las normas dominantes confucianas ${ }^{19}$.

Con base en la idea del Māhāyana, de que toda persona -hombre o mujer-posee la naturaleza búdica, la imagen negativa que se tenía de la mujer mejora. Además, es importante reconocer que los hombres que escribieron sobre las mujeres de la corriente Chan destacaron a aquellas que iluminaban y enaltecían su doctrina Chan ${ }^{20}$.

En Teachers of the Inner Chambers, Dorothy Ko realiza un estudio de la mujer y la cultura china del siglo XVII y observa que la situación de la mujer en la sangha era notoriamente diferente. Aunque dependían de los monjes, era una institución administrada por y para las mujeres. Los monjes venían de un estrato social bajo y alto, mientras que la mayoría de las mujeres eran de un estrato aristocrático. Bernard Faure señala que en el siglo VIII las monjas alcanzaron a ser casi la mitad del clérigo

jas budistas fue más diversa y compleja de lo que se informa en las fuentes oficiales. (Faure 2003, 25). Para un mayor conocimiento sobre el papel de las mujeres en el budismo indio ver Cabezón, 1985.

15 Paul 1985, 80.

16 Tsai 1994, 1. En general las monjas que se describen en este libro son de un estatus social alto. Eran monjas famosas y se consideraban mujeres sabias. Pero no se tiene ninguna idea de la vida de las monjas ordinarias, la vida común en los conventos, lo cual es una lástima.

17 Tsai 1994: 5 ss.

18 Sobre la vida de las monjas, el canon budista chino sólo incluye el Biqiuni chuan, una colección de biografías de sesenta y cinco monjas chinas, que vivieron entre principios del siglo IV y principios del VI. Shi Baochang compiló el libro en 516 y señala que eran mujeres de la aristocracia china. Aunque el documento no refleja la realidad de las monjas de aquel entonces, su contenido tiene un valor significativo (Tsai 1994, 1).

19 Hsieh 1999, 148. Esto no quiere decir que dentro del budismo no se siguiera haciendo distinciones. El famoso monje Daoxuan (596-667), de la corriente Lu-zong o de la Ley monástica, proclama el Vinaya donde las monjas tienen más de 100 reglas que los monjes que seguir y ubica a la mujer como la culpable del sufrimiento y la enfermedad del pecado que sufren los hombres, que se atribuye a la mujer por su sexualidad y crear deseo en el hombre. Es preciso agregar que, aunque hay conceptos que tienen una connotación cristiana o sugieren ideas occidentales, la palabra pecado sí es posible utilizarla en la medida en que el contenido se refiera a un contexto de pecado. Ésta, al igual que otras palabras que pueden generar dudas, como confesión, sí son adecuadas en su uso. Para un estudio más acabado de la palabra pecado en traducciones de textos budistas al castellano ver traducción y notas de Luis O. Gómez R. en Camino al Despertar, Introducción al camino del bodisatva (Bodhicaryāuvatāra), de Śāntideva, Editorial Siruela, Madrid, 2012.

20 Hsieh 1999, 149. 
chino, (ca. 120 mil personas), pero hay muy poca información del papel y su desarrollo, como también de sus condiciones de vida ${ }^{21}$.

Faure agrega que las monjas que se describen en la biografía eran visionarias y ascéticas, llevaban prácticas de concentración, vegetarianismo extremo, que caían en una idea de «anorexia sagrada $\left.{ }^{22}\right\rangle$. Desgraciadamente, no hay una sucesión de biografías, como si las hay en la de los monjes.

En Ming (1368-1644) y Qing (1644-1911) surge el concepto de huachan 花禅, que se utilizaba para referirse a las monjas que entretenían a los hombres, convirtiéndose en el periodo en el que la transformación de monjas a prostitutas alcanzó el punto más álgido ${ }^{23}$. No obstante, Beata Grant distingue un enfoque multidimensional que se manifiesta en un grupo de monjas del budismo Chan del siglo XVII, cuyos objetivos, labores y prácticas religiosas marcaron una línea distinta a la que se conocía en el mundo popular. Este grupo de mujeres, muchas de ellas viudas, decidieron seguir el camino religioso, no para entretener a aquellos hombres o monjes que las visitaban, sino para alcanzar la iluminación ${ }^{24}$.

A principios de siglo XXI, a pesar de todos los obstáculos de la época (guerras, movimientos anti religiosos, reformas, protestas y rebeliones), las reformas del maestro Taixu (1890-1947) buscaron adecuarse a un discurso religioso más modernista, que también repercutió en las monjas, quienes compartieron un discurso liberal y nacionalista. Taixu establece la Academia Budista de Wuchang para hombres y mujeres. Aquí podían entrar monjas y devotas, donde se les enseñaba literatura, filosofía y la doctrina budista. En 1931 se abrió el Vihāra del Bodhi Puro en Wuchang, en el que acudían laicas y monjas, y luego la Academia Para Monjas en Hankou. En 1949, con la llegada del comunismo al poder, esta academia se transformó en un lugar de trabajo socialista; todas las estudiantes se trasladaron a una fábrica en Wuhan y la escuela se cerró ${ }^{25}$. Después de la Revolución Cultural (1966-1976) las religiosas se reincorporaron a los conventos.

Esta breve descripción permite contextualizarnos en la historia de las bhikkhunī en China. En este desarrollo nos parece de especial relevancia la experiencia que relatan algunas de las religiosas del siglo XVII que Grant destaca, cuyas descripciones y percepciones funcionan como argumentos explicativos de lo que nuestra religiosa describirá durante su estancia en Nanwutai-shan.

\section{Un templo, una monja}

La montaña Nanwutai pertenece a la cadena montañosa Zhongnan-shan, próxima a la ciudad de Xian, en la provincia de Shaanxi. En la literatura budista que describe las prácticas extremas se hace referencia a Zhongnan como la montaña idónea para el retiro ${ }^{26}$. Famosos poetas como Libai, Dufu, Cencan y Wang Wei viajaron a la

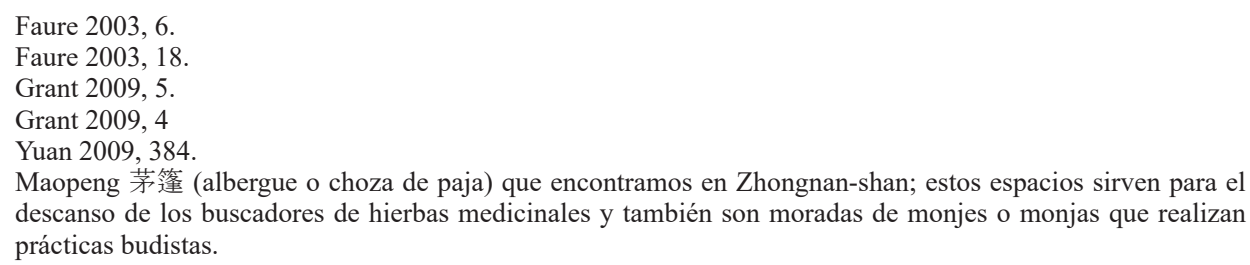


montaña y escribieron versos sobre la naturaleza del lugar. Con base en la biografía de los primeros monjes, se sostiene que desde el siglo IV Zhongnan ya era un lugar sagrado budista. Esta cadena montañosa fue lugar de origen y desarrollo de las escuelas Jingtu-zong, Huayan-zong, Lu-zong y Sanlun-zong. Maestros del Dharma habitaron e hicieron traducciones en monasterios que estaban en Zhongnan-shan o a los pies de la montaña.

El mapa antiguo de peregrinación de la montaña Nanwutai contenía una gran diversidad de templos, tangfang-miao ${ }^{27}$ y monasterios, en los que se realizaban, principalmente, prácticas daoístas, budistas y ofrecimientos a dioses de las cosechas ${ }^{28}$. Muchos de estos lugares eran administrados por laicos, pero en el transcurso de la historia, gran parte de ellos fueron destruidos, otros abandonados y algunos restaurados o vueltos a construir. Entre los templos abandonados hallamos dos de ellos, en los que usualmente moran religiosos que se instalan por un periodo de tiempo para llevar a cabo el biguan 闭关, que se traduce como 《aislarse en contemplación»o «retiro».

En 2011, durante una estancia de investigación en la montaña, observamos que un número no menor de monjas se habían instalado por un periodo para realizar prácticas de ascetismo o biguan en la montaña. Entre este grupo, de alrededor 8 religiosas, encontramos a Fachuan 法传, una monja que habitaba en el templo abandonado Sansheng-dian 三圣殿.

El templo Sansheng-dian se encuentra en las faldas de la montaña, en el sendero de los peregrinos. En las fuentes bibliográficas de Nanwutai-shan o en las estelas que se han rescatado del lugar no se menciona nada sobre el origen de este templo, pero sí se señala que, en 1996, gracias a devotos de la ciudad de Xian, se logró restaurar. En 1998 se destruyó parte de la estructura del edificio y después se volvió a construir. Dentro del salón principal del templo está el Buda Amituo (Amitābha) acompañado de cuatro bodhisattvas. A un costado del salón hay otra edificación donde está la cocina y una habitación.

Con el paso del tiempo el templo quedó abandonado y durante ciertos periodos se utiliza como morada y lugar de retiro para religiosos daoístas o budistas.

En 2011 la monja Fachuan viajó por segunda vez a Zhongnan-shan para practicar en el Sansheng-dian. Ella señaló que era divorciada y tenía un hijo adolescente. Se hizo monja el día 27 del séptimo mes de 2007. Fachuan junto a una amiga llegaron a un monasterio en la provincia de Jiangsu, para conversar con el abad acerca de su intención de ser monjas. El abad, al ver el entusiasmo de Fachuan, le hizo la tonsura en ese mismo momento. Después partió a un monasterio en Guangdong y luego a Fujian, para finalmente regresar a una villa en Jiangsu, donde se estableció en un pequeño templo.

Fachuan recuerda al abad de Jiangsu con gran admiración, ya que estuvo siete años, intermitentemente, en biguan, y logró el segundo grado de santidad en el camino del luohan (arhat), el situohan (sakrdāgāmin), que significa que sólo renacerá una vez más antes de alcanzar el nirvāṇa.

\footnotetext{
27 Los tangfang-miao 湯房庙 son templos que administran los devotos laicos, y en ellos se recibe a los peregrinos durante la fiesta del guohui o miaohui.

28 Sobre la peregrinación en Nanwutai-shan y las experiencias de los devotos y peregrinos en la montaña ver María Elvira Ríos, El reflejo de la luna en la montaña: el budismo en Nanwutai-shan, tesis de doctorado, Centro de Estudios de Asia y África, El Colegio de México, 2015.
} 


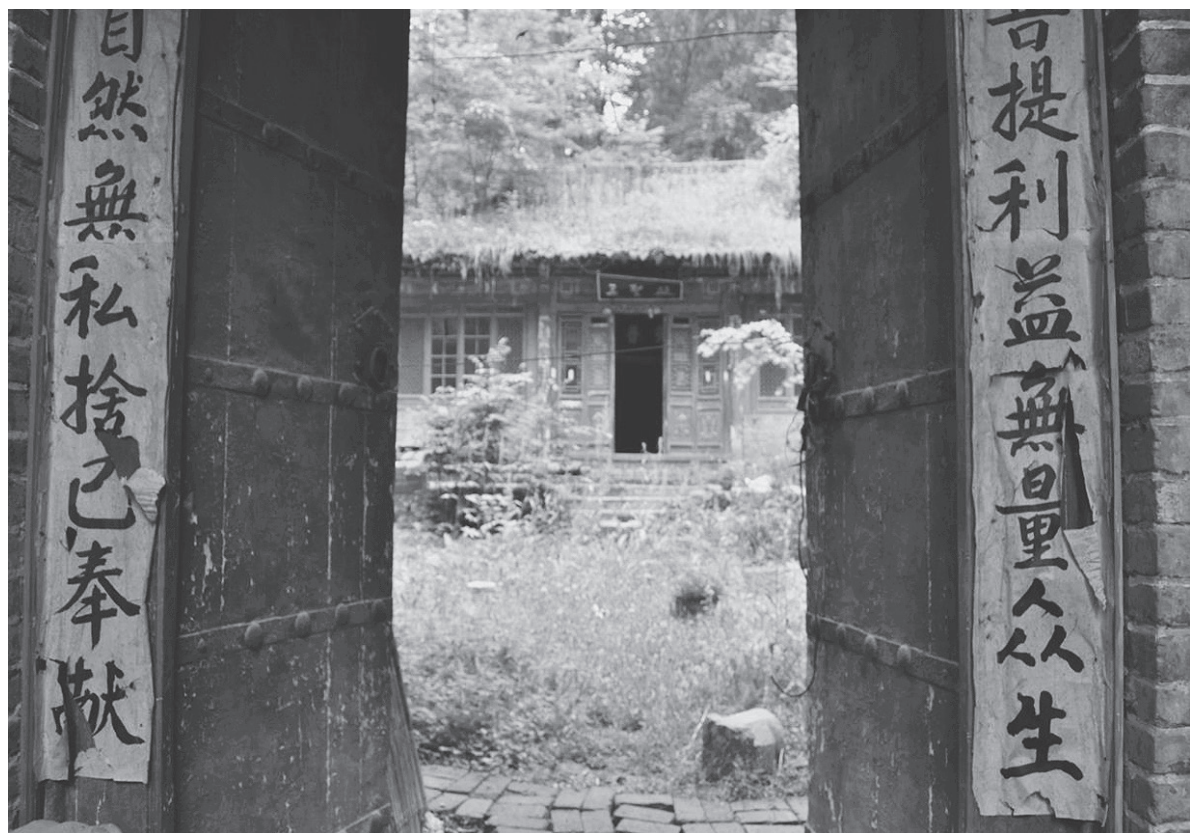

Figura 1. Templo Sansheng-dian (fotografía de María Elvira Ríos)

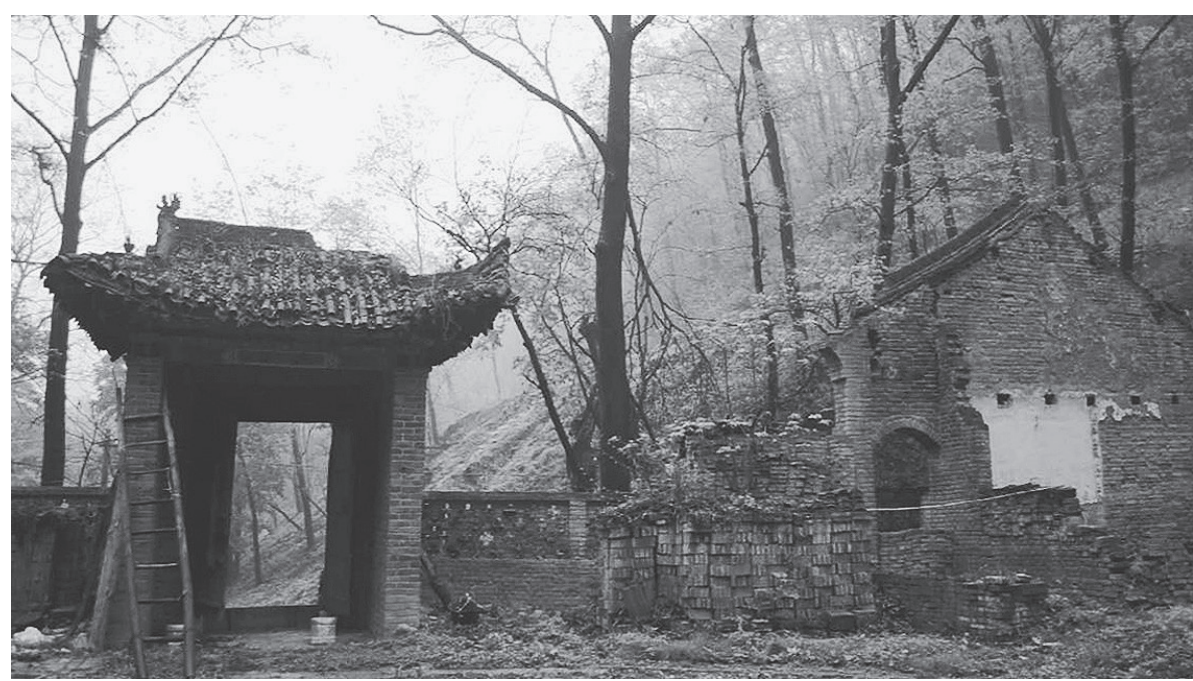

Figura 2. Templo Sansheng-dian (fotografía de Omar Alfonso Liévano)

La figura del luohan, es un ideal en las prácticas de Fachuan, y por ello va a las montañas donde es posible realizar prácticas ascéticas. Viaja a Zhongnan-shan porque conoce la historia del lugar y porque sabe que monjes eminentes habitaron en esa montaña.

Durante las conversaciones que entablamos con Fachuan pudimos observar y analizar el trabajo espiritual en el que la religiosa concentraba sus prácticas. Es inte- 
resante señalar que Fachuan hizo hincapié en que se alejó del ambiente eclesiástico debido a la debilidad de las enseñanzas de los maestros actuales. Esto último nos sugiere que en ella hay una doble intención de abandono: la primera para retirarse y realizar prácticas de ascetismo, y la otra para alejarse del ambiente eclesiástico. Fachuan recomienda leer los sūtras y no los libros que escriben los monjes de hoy, porque duda de la profundidad de sus conocimientos y de su dedicación a la práctica:

[...], ahora todos quieren escribir libros, pero en el pasado los monjes eminentes no hablaban ni escribían, porque lo más elemental del Buda está en los sūtras. Nosotros practicamos desde la enseñanza de los sūtras y no desde lo que un monje escribió en un libro. Los escritos de los monjes antes de la dinastía Song expresan puntos de vista conforme a las escrituras y nos indican los sūtras de donde toman sus enseñanzas, pero ahora nadie hace eso.

El lugar que Fachuan eligió para concentrarse en las antiguas enseñanzas se había fusionado lentamente con la naturaleza. Los tonos grises y colores gastados del templo Sansheng-dian se mimetizaron con el bosque, actuando como un camuflaje que sólo el paso del tiempo lo permitía. En la estética del templo se percibía aquella belleza imperfecta, plasmada en los conceptos de wabi 侘 y sabi 寂. Ambos términos, de origen chino pero desarrollados en Japón, sugieren cualidades como efimero, humildad, asimetría e imperfección ${ }^{29}$. Leonard Koren destaca tres características naturales de las cosas que definirían ambos conceptos: todas las cosas son efímeras, todas las cosas son imperfectas y todas las cosas son incompletas: «Aceptación de lo inevitable. Wabi y sabi es la apreciación estética de la evanescencia de la vida (...). Las imágenes wabi-sabi nos fuerzan a contemplar nuestra propia mortalidad, y evocan una sola y delicada tristeza ${ }^{30} \gg$. Estas características de wabi sabi, vinculadas con el pensamiento daoísta y budista, y representadas en el templo abandonado, servirán como analogía a lo que la religiosa interpreta sobre su propia intención de práctica interior. Asimismo, estas características estéticas logran que el templo se mimetice con el paisaje, logrando crear un espacio escondido en la montaña. La idea de lo escondido u oculto es inherente en el concepto de retiro. El concepto chino más común que se utiliza para referirse a eremita es yinshi 隐士, cuyo primer carácter significa «oculto». De ahí que la palabra yinshi se puede traducir como «el erudito oculto».

\section{Unión de espacios: percepción de la conciencia plena}

En aquel templo rodeado de malezas, de muros en ruinas y tejas desquebrajadas, Fachuan decidió instalarse. Un monje budista del templo Baiyi, ubicado a cercanos metros del Sansheng-dian, había invitado a Fachuan a quedarse en su templo, donde contaba con alimento, baño, ropa y protección. No obstante, Fachuan, agradeciendo la atención, sólo accedió a bañarse de vez en cuando en el Baiyi, pero sabía que aquel lugar no era el adecuado para su práctica. La soledad del Sansheng-dian, privilegio 


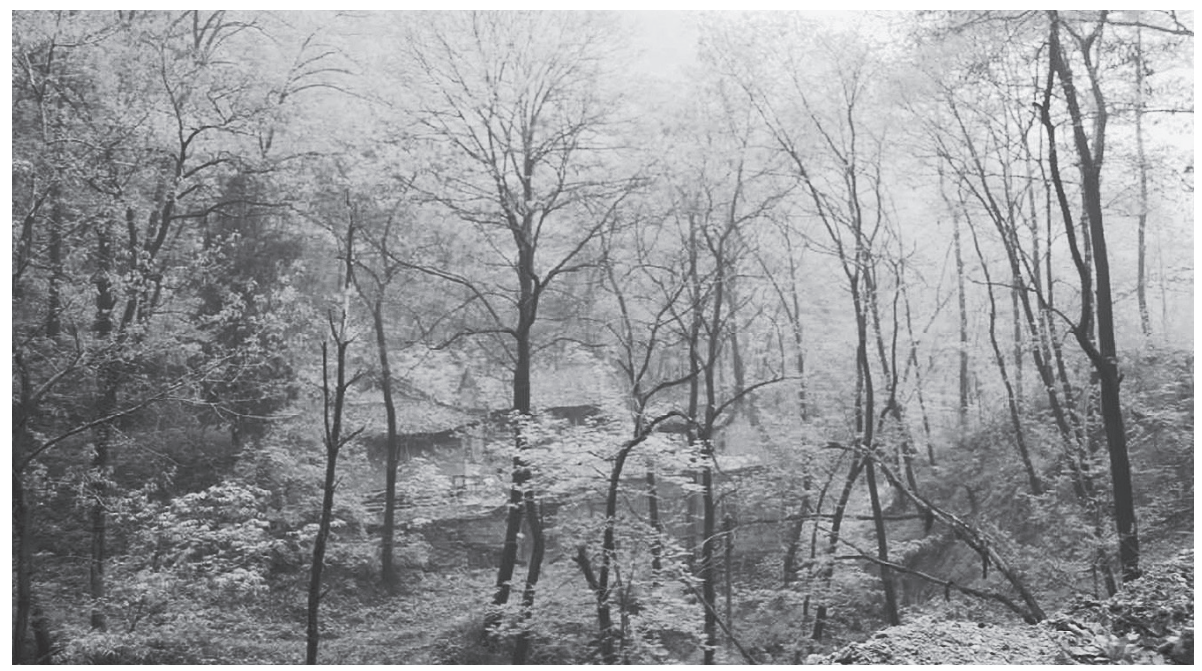

Figura 3. Templo Sansheng-dian Nanwutai-shan (fotografía de Omar Alfonso Liévano)

difícil de conseguir en China, como también la precariedad del templo, la conectaba con la verdadera práctica, ardua y compleja, que debía realizar en su interior, para liberarse y alcanzar un nivel superior de conciencia.

Y es que la estética del templo abandonado pareciera despertar visualmente la intención de abandono interior que manifiesta Fachuan al referirse a su práctica. La religiosa señaló querer alcanzar el estado de luohan y su interpretación de este nivel superior de conciencia la relató, a propósito de una experiencia de su maestro:

Cuando [el maestro] entra en estado de contemplación, logra separarse del cuerpo. ¿Cómo se puede hacer esto? Es como un pájaro encerrado en su jaula, nuestras facultades mentales están encerradas en el cuerpo, pero cuando el maestro entra en estado de contemplación, su mente puede escapar, como el pájaro que se echa a volar y en el momento que quiere regresa a su jaula, pues ésta se queda ahí, igual que el cuerpo.

Fachuan realiza una analogía entre la jaula y el cuerpo, como si este fuera una cápsula cuya llave para abrir solo la tiene las facultades superiores de nuestra mente. Es muy interesante la similitud de esta interpretación con la experiencia que describe la maestra Qiyuan Xinggang (1597-1654), quien ha sido considerada la matriarca de las maestras de la corriente Chan de su época. Qiyuan siguió las enseñanzas de su maestro Miyun Yuanwu (1566-1642), cuya rigurosidad en la práctica se manifiesta en la siguiente enseñanza dirigida a una de sus herederas del Dharma: «sólo cuando las cosas son difíciles uno puede ver la gran mente (zhangfu xin); solo cuando la estación es fría uno puede ver el verde de los pinos y los cipreses ${ }^{31} \gg$. Entre las diversas experiencias que Qiyuan describió sobre sus retiros de meditación, encontramos una en la que se refiere al resultado de su práctica perseverante: 
Vivía en profundo aislamiento con pocas comodidades, pero determinada a perseverar. Mi cuerpo [sentado y con la espalda recta] con recatada dignidad, [no distinguía entre] el interior y el exterior. Puse resistencia al vacío cortando los enredos. Una vez que [la distinción entre] el interior y el exterior (había desaparecido), todos los enredos quedaron anulados. Cuando no hay forma ni figura, entonces uno puede ver su propio rostro [original], puede concentrar grandes eones de tiempo en un solo punto y extender una mota de polvo en las diez direcciones. [Entonces uno experimenta] el no tener restricciones, o limitaciones, [y es] libre de ir donde le plazca ${ }^{32}$.

A pesar de la lejanía temporal de ambas descripciones, tanto Fachuan como Qiyuan se refieren a la práctica de meditación y experiencia como una liberación corporal, en donde se pierde el límite entre lo externo e interno, ya que al liberarse de las ataduras se es posible deambular sin restricciones espaciales. ¿Cómo es posible lograr ese estado?, Fachuan responde que es preciso liberarse de los sentidos que nos tienen atados a este mundo:

La función del ojo es ver y a eso se le llama yanshi眼试, y así con todos los sentidos (ershi 耳试, bishi 鼻试, sheshi 舌識, shenshi 身識, yishi 意識) $)^{33}$. Cuando una persona muere, los seis órganos, liugen 六根, todavía están ahí, pero los seis shi se van; la facultad de distinguir, de percibir o reconocer o discernir, ya no es posible. Entonces, si una persona muere y ya no tiene los liushi, ¿a dónde van estos liushi?; estos liushi no se dividen en seis, sino que se funden en lo que se llama el shenshi, 神識 ${ }^{34}$. El shenshi también es la base del karma de las vidas anteriores, por esto también se llama yeshi 業識 35 , envuelve el karma bueno y malo y del cual dependerá el estado en el que se vuelva a renacer.

Al shenshi la gente extranjera lo llama linghun 靈魂 $^{36}$, nosotros no lo llamamos así, pero es más o menos la misma idea.

Después de que Fachuan realiza esta breve introducción de los liushi y shenshi, comienza a explicar la manera de llevar a cabo una profunda meditación:

Al morir una persona el shenshi sale del cuerpo, pero también es posible que esto ocurra sin tener que morir, pues también es posible mediante la meditación. Debemos lograr una meditación en la que los sentidos no se utilicen y tampoco se dividan, de esta manera logramos que nuestro shenshi se separe del cuerpo. Después de eso podemos usar nuestros sentidos, que ya están puros. Esto último es posible con miaoxin 妙心 ${ }^{37}$, lo contrario a wangxin妄心 ${ }^{38}$; todos tenemos miaoxin, pero muchos no lo han encontrado y yo tampoco, pero ya empecé el camino en busca de ese miaoxin, por medio de la lectura de más de cien sūtras, sobre cuya enseñanza he ido reflexionando durante muchos años.

\footnotetext{
Grant 2009, 51.

Los seis shi son la consciencia de los órganos de los sentidos, contando a la mente como un órgano sensorial.

El shenshi, 神識, la inteligencia, el espíritu, que también se llama linghun 靈魂 (Soothill y Hodous 1937, 335).

Yeshi es la actividad consciente perturbada por la ignorancia y las acciones del individuo.

Podemos suponer que con el término linghun se refiere al concepto de «alma.»

37 Miaoxin es la mente-corazón profunda y extraordinaria que va más allá del pensamiento humano (Soothill y Hodous 1937, 234.

38 Wangxin es la mente errada, falsa, ilusoria (Soothill y Hodous 1937, 210).
} 
En una primera explicación, Fachuan se refiere a cómo los sentidos se funden con el shenshi de la persona que ha fallecido. Este shenshi sale del cuerpo y, al contener el karma de la persona, renacerá según sus acciones del pasado. Fachuan agrega que en una meditación superior es posible adquirir la capacidad de lograr, en vida, la no utilidad de los sentidos y liberar al shenshi de nuestro cuerpo. Al lograrlo, los sentidos en estado puro pueden unirse al shenshi.

Ahora bien, si tomamos en cuenta la interpretación de Fachuan, es posible observar cómo la práctica que ella describe para alcanzar un estado de meditación profunda se entiende, en un principio, abandonando los sentidos que nos provocan las turbaciones internas, y así el espíritu shenshi logra abandonar el cuerpo. Este abandono que realiza el shenshi es, más bien, un salir del cuerpo para luego volver, es decir, el cuerpo per se, ya no es una cápsula, una jaula en la que nos encontramos inmersos, atados a sus deseos. Asimismo, los sentidos en estado de pureza permiten discernir entre lo real y lo no real.

Con la explicación anterior se puede inferir que, el cuerpo de aquel practicante que alcanza una conciencia plena queda abandonado y, al igual que el templo, se convierte en ese espacio desalojado que el practicante habita de vez en cuando, al que va y vuelve, pero que lo deja tal cual como está, porque es esa apariencia de abandono la que determina la liberación de las perturbaciones.

La práctica de abandonar el cuerpo en el budismo se ha interpretado de distintas maneras. Una de ellas es la inmolación, la que se cree que su origen se debe a inspiraciones de los religiosos en los jătakas, historias de las vidas del pasado del Buda. En China ha sido una práctica que tuvo un auge importante durante la dinastía Tang (618-907). Un dato peculiar es que no menos de 5 de las 10 historias que se cuentan sobre inmolación en el Xu Gaoseng zhuan, compilado por el maestro Daoxuan (596667), se efectuaron en la montaña Zhongnan-shan. Daoxuan destaca estas inmolaciones como respuesta a la persecución que estaba viviendo el budismo, llevadas a cabo por el emperador Zhou Wudi (560-578), que inician en el 574. Los monjes abandonan sus cuerpos, pero como un acto de ofrecimiento que, de igual modo, responde a una acción contra las políticas de persecución ${ }^{39}$.

A diferencia de este tipo de abandono, en el que se produce una desintegración total del cuerpo, Fachuan recalca en la capacidad de abandonar el cuerpo como un estado superior de meditación y, por lo tanto, de conciencia. De esta manera, se puede interpretar que, en el momento en que el shenshi observa con el sentido puro de la visión a ese cuerpo abandonado, lo realiza con el discernimiento maravilloso, lo que Fachuan describe como miaoxin. La religiosa asegura saber cómo encontrar su miaoxin, y conforme lo vaya descubriendo podrá ir alcanzando el primer nivel hasta llegar al cuarto y convertirse en un luohan. En ese momento el miaoxin todavía será una consciencia limitada, «porque aún más vasto que todo es el miaoxin del fajie 法界, cuando logras entender todo el universo».

Fachuan finaliza su interpretación agregando el concepto de fajie, una idea crucial en el pensamiento budista y que en China fue adquiriendo distintas connotaciones. Fajie, (dharmadhātu en sánscrito) es la realidad última, la realidad absoluta pero inmanente de todas las cosas. En general, se refiere a todas las cosas que se pueden percibir con las facultades sensoriales (en estado puro), vistas con la cons-

39 Benn 2007, 79 s. 
ciencia de un ser liberado. También se refiere al universo físico, en el que el tiempo, el espacio y todos los seres vivos son elementos constituyentes ${ }^{40}$. En la corriente Huayan, el dharmadhātu se identifica como la realidad que vive un Buda. En el Gaṇdavyūha, del Sütra Huayan (Avatamssaka), se relata la peregrinación del joven Shancai (Sudhana), quien visita a cincuenta y dos - o cincuenta y tres-kalyānamitra, «amigos del bien ${ }^{41}$ ». En este texto, los dos mundos, lokadhātu -la esfera mundanay dharmadhātu - la esfera de la liberación y el despertar- se consideran idénticos ${ }^{42}$. Imre Hamar destaca que, según esta corriente, todas las cosas o fenómenos representan la directa y completa manifestación de la esencia. Sustancia y función, así como esencia y fenómeno existen en un estado de entremezcla perfecta. Fazang (643-712) explicó esta relación con los términos «verdad» (zhen 真) y falso (wang 妄), señalando que lo verdadero gobierna lo falso y no hay aquello falso que no pueda ser verdadero. Ambos están entremezclados y se insertan uno con otro sin obstrucción ${ }^{43}$. El maestro Zongmi (780-841) enfatiza en esta perfecta combinación de las cosas (shi 实) y principio (li理). Se opone a hablar de dharmadhātu de las cosas (lokhadātu) de manera aislada al dharmadhātu del principio. Es decir, el mundo, desde la mirada de la corriente Huayan es tanto sustancia y fenómeno, por lo tanto, es también liberación y samsāra ${ }^{44}$. Peter Gregory concluye que Zongmi entiende el dharmadhātu en términos de tathāgatagarbha (foxing 佛性), la naturaleza búdica ${ }^{45}$.

$\mathrm{Si}$ incorporamos todo este contenido doctrinario de la corriente Huayan a la experiencia de meditación que relata Fachuan es posible sugerir que, el practicante, al lograr separarse del cuerpo, su comprensión y percepción de la unión entre la realidad fenomenal y sustancial de las cosas, se manifiesta con mayor claridad al observar que aquel espacio en el que habita, aquel lugar en donde se han abandonado los sentidos, se hace uno con la naturaleza, con aquello que guarda el $l i$, el principio de las cosas. Si lo entendemos de esta forma, entonces el templo abandonado, se convierte en la representación de la unión de los fenómenos con lo sustancial y, de la misma manera, reflejo del abandono corporal que experimenta el practicante. Desde esta perspectiva se deduce que el templo abandonado se convierte en el lugar idóneo para la meditación profunda. El practicante, al descubrir el verdadero dharmadhātu, también encuentra su foxing, su naturaleza búdica. Este mismo descubrimiento o percepción se puede entender con las palabras de Anne Klein que destaca Grant, cuando se refiere a la experiencia de la maestra Qiyuan durante su retiro: «la conciencia plena disminuye el sentido de estar atrapado 'dentro' de uno mismo, o estar aislado del gran mundo. Este espacio subjetivo no se encuentra confinado dentro del cuerpo, porque ir lo suficientemente hacia 'adentro' es también un punto de conexión con el vasto mundo ni-externo-ni interno ${ }^{46}$ »).

\footnotetext{
Traducción al castellano de Luis O. Gómez Rodríguez para la palabra en sánscrito dharmadhātu.

Traducción al castellano de Luis O. Gómez Rodríguez, para la palabra en sánscrito kalyanamitra.

Cabezón 1992, 95 ss.

Hamar 2007, 190.

Hamar 2007, 191.

45 Gregory 1995, 12 s. Gregory remite a la interpretación de Zongmi y del maestro Fazang 法藏 (643-712) sobre el término dharmadhātu, en el Sūtra Huayan. Fazang afirma que se pueden entender tres significados para dhātu; la causa (yin因), la naturaleza (xing 性) y lo diferenciado fenqi (分齊). De acuerdo con el primer y segundo sentido de dhātu, dharmadhātu se refiere a la causa para la realización del noble sendero, o a la naturaleza oculta de la realidad fenomenal. En cualquier caso, el significado se acerca a la idea de tathāgatagarbha (Gregory 1995, 13), que también se traduce en chino como foxing, la naturaleza búdica.

46 Grant 2009, 51.
} 
Además de lo ya señalado, es interesante agregar otra desarticulación de división espacial que señala Grant, a propósito de la conciencia plena (smrti) que alcanzan las maestras de la corriente Chan; esta conciencia puede también borrar los límites convencionales entre lo público y lo privado ${ }^{47}$. Al trasladar esta interpretación a nuestro análisis nos preguntamos ¿qué otro espacio, que no sea un lugar abandonado, rompe con la división espacial entre lo público y lo privado? Y es que el espacio abandonado, justamente, permite liberarnos de esa limitación creada por la sociedad, lo cual le concede un estado singular que favorece al practicante.

En la unión de ambos espacios (exterior-interior) o realidades (fenomenal-principio) el estímulo-respuesta, ganying, se convierte en una constante. El espacio del templo abandonado en la montaña estimula al practicante a mantenerse en ese lugar y conectarse con este «adentro y afuera». A su vez, esta interacción le permite tener ganying no sólo con el espacio, sino con los budas o bodhisattvas. Esto último se ejemplifica con la siguiente experiencia que tuvo Fachuan en el templo: mientras ella se encontraba en el Sansheng-dian, el bodhisattva (no sabemos cuál) solía anunciarle la llegada de algún visitante. Esta manera de tener ganying se entiende cuando los budistas chinos hallaron en los sūtras mahāyānas, como el Sūtra del Loto, la idea de que los budas y bodhisattvas eran capaces de asumir diferentes formas y manifestarse entre los humanos en respuesta a sus necesidades ${ }^{48}$. Daniel Stevenson, en su análisis de los cuentos del Sütra del Loto, describe ganying como una estructura discursiva china de «estímulo» (gan) y «respuesta» (ying) ${ }^{49}$. Los devotos pueden sentir el «estímulo» que los conecta con la divinidad, e incluso les permite visualizar o soñar con el bodhisattva y observar luces en el cielo. A esta percepción de lo «sobrenatural» que se tiene en el lugar sagrado, se le llama ganying, la respuesta a la petición que interactúa de manera recíproca; hay una correspondencia entre el devoto y la divinidad (Soothill y Hodous, 1937: 399).

\section{Conclusiones y reflexiones finales}

En este análisis exploratorio se puede inferir algunas cosas que, más que concluir, sugieren atender sobre las prácticas de religiosas budistas en China. Se ha querido destacar el papel que cumple el templo abandonado durante las prácticas de meditación que describe la religiosa. La estética del templo y lo que ésta transmite funge como un elemento analógico a la experiencia y percepción de abandono del cuerpo. Ésta, descrita con los conceptos de wabi y sabi, describe visualmente la experiencia de abandono del cuerpo y liberación del shenshi. De lo anterior se deduce que la analogía cuerpo-templo abandonado, representa lo efímero del mundo fenomenal $y$, de la misma manera, la unión de esta realidad fenomenal con la realidad sustancial, logrando entender el dharmadhātu universal. Desde esta percepción, alcanzada con una visión pura, se logra el estado de conciencia plena, donde las distinciones entre lo interior-exterior y lo público-privado desaparecen. El templo abandonado se convierte en el espacio que, quizá, mejor caracteriza esa no distinción. El factor de «abandono» es fundamental para lograr esta interpretación.

\footnotetext{
47 Grant 2009, 51.

48 Faure 2003, 7.

49 Stevenson 1995, 429.
} 
El puente o hilo conductor entre el templo abandonado y la práctica interior es ganying. Este estímulo-respuesta que la religiosa percibe con el lugar y con el bodhisattva, produce una suerte de seguridad y protección, como también de conexión con la realidad sustancial. Esta última se manifiesta cuando el practicante logra liberarse de las turbaciones y discierne la unión entre esa y la realidad fenomenal. La mimetización del templo abandonado con la naturaleza actúa como metáfora de esa unión, adquiriendo una característica estética que se fusiona con la naturaleza.

Por último, al tratarse de una monja, la imagen del templo abandonado adquiere una doble connotación, pues aunado a lo ya señalado, se agrega el valor que adquiere el lugar como refugio de quien escapa de la estructura eclesiástica y las falsas enseñanzas. El templo abandonado es para Fachuan un espacio de ausencia de jerarquías, de reglas monásticas y ritos: esto último no quiere decir que la religiosa no hubiera realizado los ritos respectivos o que no haya venerado a las imágenes de los budas y bodhisattvas del templo. Lo que se quiere señalar es que, al romperse la división espacial, también se quiebra las divisiones y jerarquías que el clero instaura: el templo abandonado es reflejo de ausencia del orden impuesto por la sociedad religiosa.

En torno a esta experiencia de aislamiento de una monja religiosa es que se invita a reflexionar y atender sobre las ideas y conjeturas planteadas, para entender de mejor manera el modo y los elementos que influyen en las prácticas de aislamiento de monjas budistas en China, y el papel que adquiere el templo abandonado.

\section{Bibliografía}

J. Arnau, Antropología el Budismo, Editorial Kairós, Barcelona, 2007.

N. J. Barnes, «The Nuns at the Stūpa: Inscriptional Evidence for the Lives and Activities of Early Buddhist Nuns in India», Women's Buddhism Buddhism's Women. Ed. E. Banks, Wisdom, Somerville, 2000, 17-36.

J. A. Benn, Burning for the Buddha, self immolation in Chinese Buddhism, Kuroda Institute, University of Hawai'i Press, Honolulu, 2007.

K. R. Blackstone, Women in the Footsteps of the Buddha. Struggle for the Liberation in the Therīgāthā, Curzon Press, Britain, 1998 (reimpr. Delhi, 2000).

J. I. Cabezón, Buddhism, Sexuality, and Gender, State University of New York Press, Albany, NY, 1992.

B. Faure, The Power of Denial: Buddhism, Purity, and Gender. Princeton University Press, Princeton, NJ, 2003.

A. C. Graham, Disputers of the Tao: Philosophical Argument in Ancient China, Open Court Editions La Salle, IL, 1989.

P. Gregory, Inquiry into the Origin of Humanity: An Annotated Translation of Tsung-Mi's Yuan Jen Lun with a Modern Commentary (Classics in East Asian Buddhism), University of Hawai'i Press Honolulu, HI, 1995.

L. O. Gómez. R., (Introducción, traducción y notas). Camino al Despertar, Introducción al camino del bodisatva (Bodhicaryāvatāra) de Śāntideva, Editorial Siruela, Madrid, 2012.

I. Hamar, Reflecting Mirrors, Perspectives on Huayan Buddhism, Harrassowitz Verlag, Wiesbaden, 2007

D. E. Hsieh, «Images of Women in Ch'an Buddhist Literature of the Sung Period», Buddhism in the Sung. Ed. P. Gregory, University of Hawai'i Press, Honolulu, HI, 1999, 148-187. 
A. Juniper, Wabi Sabi, the Japanese Art of Impermanence, Tuttle Publishing, United States, 2003.

L. Koren, Wabi-Sabi for Artists, Designers, Poets \& Philosophers, Stone Bridge Press, Berkeley, CA, 1994.

D. Paul, Women in Buddhism. Images of the Feminine in the Mahāyāna Tradition. University of California Press, Berkeley, CA, 1985.

R. Sharf, Coming to Terms with Chinese Buddhism, University of Hawai'i Press, Honolulu, HI, 2002.

W. E. Soothill y L. Hodous, A Dictionary of Chinese Buddhist Terms 中英佛學辭典. With Sanskrit and English Equivalents and a Sanskrti-pali index [incluye un breve índice de términos tibetanos, pp. 509-510], K. Paul, Trench, Trubner \& co., ltd London, 1937.

D. Stevenson, «Tales of the Lotus Sutra», Buddhism in Practice D. S. Lopez, Jr., Princeton N.J.: Princeton University Press, 1995, 427-451.

K. A., Tsai (Trad.), Lives of the Nuns: Biographies of Chinese Buddhist Nuns from the Fourth to Sixth Centuries, a Translation of the Pi-ch'iu-nichuan. Comp. Shih Pao-ch'ang. University of Hawai'i Press, Honolulu, HI, 1994.

Y. Yuan. «Chinese Buddhist Nuns in the Twentieth Century: A Case Study in Wuhan», Journal of Global Buddhism, Vol. 10,375-412, 2009, http:/www.globalbuddhism.org/10/ yuan09.pdf [acceso: 15/10/2016]

Q.H. Zhang y J.J. Min, 试论《周易》中的隐遁思想一兼论对儒家的影响, 2016, https:// www.sinoss.net/uploadfile/2016/0504/20160504050214936.pdf [acceso: 06/12/2016] 